\title{
Women's body dissatisfaction, social class, and social mobility
}

\author{
Lindsay McLaren ${ }^{\mathrm{a}, *}$, Diana Kuh ${ }^{\mathrm{b}}$ \\ ${ }^{a}$ Department of Community Health Sciences, Faculty of Medicine, University of Calgary, G230 Health Sciences Building, \\ 3330 Hospital Drive NW, Calgary, Alta. T2N 4N1, Canada \\ ${ }^{\mathrm{b}}$ MRC National Survey of Health and Development, University College London, UK
}

\begin{abstract}
Several studies indicate that socially advantaged women are more dissatisfied with their bodies than socially disadvantaged women. These findings have been based on women's current social class, and no attention has been paid to the social class of her family of origin or to intergenerational social mobility. In the present research 91254 -year-old women from a prospective birth cohort study provided self-report data on current body esteem (appearance and weight dimensions). Childhood and adult social class (manual versus non-manual) were defined based on father's occupation and own or partner's occupation, respectively. This information and the highest educational qualifications recorded by age 26 were gathered prospectively. Indicators of current and adolescent body mass index (BMI) were computed from height and weight values collected at ages 15 (or 11) and 53-54 years. Multiple regression was used to examine the relationship between midlife body esteem and childhood social class, adult social class, educational qualifications, and social mobility, unadjusted and adjusted for BMI. Women from the non-manual classes as adults were more dissatisfied with their weight than women from the manual classes as adults, for a given BMI. Adjusting for BMI, downwardly mobile women were more satisfied with their appearance than stable non-manual women. Adjusting for BMI, higher educational qualifications were associated with more dissatisfaction with weight and with appearance, and education appears to be more important than occupationally defined social class in explaining body dissatisfaction. A clearer understanding of the relationship between socio-economic position and body dissatisfaction demands that the following distinctions are made: weight versus appearance satisfaction, education versus occupation, and current social class versus intergenerational social mobility.
\end{abstract}

(C) 2003 Elsevier Ltd. All rights reserved.

Keywords: Body dissatisfaction; Social mobility; Prospective cohort

\section{Introduction}

In general, research has demonstrated that for a given body size, socio-economically advantaged women are more dissatisfied with or concerned about their bodies than socio-economically disadvantaged women (Ogden \& Thomas, 1999; Wardle \& Griffith, 2001). An explanation concerns the role of thinness as a marker of social distinction in industrialised society (Bordo, 1993), which makes it more likely to be valued by individuals higher on the socio-economic spectrum.

\footnotetext{
*Corresponding author. Tel.: +403-210-9424; fax: +403210-3818.

E-mail address: lmclaren@ucalgary.ca (L. McLaren).
}

Sociological authors have highlighted social class differences in the extent to which investment in and control over the body is considered a 'project' worthy of time and effort (Bourdieu, 1984), a perspective which predicts that socio-economically advantaged individuals are more likely to aspire to, and invest effort in attaining a particular bodily appearance (which at the present time is thin).

The interrelationship between socio-economic position, body size, and body dissatisfaction is more relevant for women than for men. There is a clear social stratification of body size among women in modern societies with a larger average body size and a higher prevalence of obesity among socially disadvantaged than among socially advantaged women (Wardle, 
Waller, \& Jarvis, 2002; Sobal, 1991; Sobal \& Stunkard, 1989). This relationship is not as strong or as consistent among men (Wardle et al., 2002; Sobal \& Stunkard, 1989). Obesity appears to be more strongly stigmatised in women than in men, and there is evidence of demonstrable consequences experienced by women for being obese. Based on US data, Gortmaker, Must, Perrin, Sobol, and Dietz (1993) found that women who had been overweight during adolescence had more negative outcomes 7 years later, including completion of fewer years of school, being less likely to be married, and having higher rates of household poverty, relative to women who had not been overweight. Based on British data, Sargent and Blanchflower (1994) showed that women who had been obese at age 16 earned significantly less at age 23 than women who had not been obese at age 16; this finding was independent of parental social class and baseline ability test score, and was not obtained among men in the sample. Body dissatisfaction is strongly related to body size in females, with larger women more likely to be dissatisfied (Allaz, Bernstein, Rouget, Archinard, \& Morabia, 1998; Reboussin et al., 2000). Not surprisingly, the evidence is clear that concern with and distress about bodily appearance (particularly weight) is a highly gendered phenomenon. Women score higher than men on almost any indicator of dissatisfaction with their own bodily appearance (Feingold \& Mazzella, 1998). Dissatisfaction with weight is so common among women as to be considered a 'normative discontent' (Rodin, Silberstein, \& StriegelMoore, 1985).

Pervasive dissatisfaction with one's weight among women is widely blamed on ubiquitous images of extremely thin women in the media. These media images portray extreme thinness as typical and attainable by all women, and they convey the powerful message that thinness is a prerequisite for physical beauty. This message is believed to have emerged in the mid-1960s with the arrival of 'Twiggy', a fashion model for women who had a childlike body (Brumberg, 1988). There is good evidence that the current 'ideal' of female beauty, operationalised in terms of the size of women presented in the media, is vastly smaller (particularly thinner, but also taller) than the average woman (Spitzer, Henderson, \& Zivian, 1999). And, experimental studies show that exposure to these images negatively impacts on the body image of girls and women who inevitably feel that, against this stringent standard, it is impossible to 'measure up' (for a review see Groesz, Levine, \& Murnen, 2002). Feminist writers (e.g., Orbach, 1978) suggest that body dissatisfaction and eating disorders are an inevitable result of a fundamentally misogynistic society that facilitates these outcomes in women by objectifying their bodies and devaluing their experience. Thus, socio-cultural and feminist perspectives provide viable explanations for the preponderance of body dissatisfaction in women versus men. However, their utility in explaining social class differences in body dissatisfaction among women is more limited.

Individual socio-economic position is not a unidimensional construct, and may be defined in a number of ways including occupation, education, and income. Each of these indicators has been examined for an association with body dissatisfaction or some related construct (e.g., dieting, weight monitoring), and results are not entirely consistent. Among US adult women, Jeffery and French (1996) found that likelihood of dieting increased with increasing income, and that higher income women reported that they would notice a smaller amount of weight gain than lower income women. However higher and lower income women did not differ in the importance they ascribed to body weight, nor in their desired body mass index (BMI). Using a nationally representative British sample, Wardle and Griffith (2001) found that women with higher occupationally defined social class were more likely to perceive themselves as overweight, to monitor their weight more regularly, and were more likely to be trying to lose weight, despite being lighter on average. Jeffery, Adlis, and Forster (1991) studied education in relation to dieting among US adult women, and found that those with more formal education were more likely to have dieted in the past, but were no more likely to report current dieting, than women with less education. Although various indicators of socio-economic position have been examined in relation to body dissatisfaction, it is not clear which indicator is most important in this context. One goal of the present study is to evaluate the association of both occupationally defined social class and education with body dissatisfaction and determine which is the more important determinant.

Existing research on social class and body dissatisfaction has dealt exclusively with women's current socioeconomic position, with little or no attention paid to the socio-economic position of her family of origin. Furthermore, to our knowledge there are no studies addressing social mobility over the life span as it relates to adult body dissatisfaction. Research has shown an association between social mobility and obesity, with upward social mobility reducing the likelihood of being obese in comparison with those who remain in the manual classes (Langenberg et al., 2003). ${ }^{1}$ Also women who come from lower social class origins are likely to increase in weight more rapidly throughout adulthood (Hardy, Wadsworth, \& Kuh, 2000). The close relationship between body size and body dissatisfaction

\footnotetext{
${ }^{1}$ Correspond to: Claudia Langenberg, MRC National Survey of Health and Development, Department of Epidemiology and Public Health, University College London, 1-19 Torrington Place, London, WC1E 6BT, UK. Tel.: 020-7679-1720, fax: 0207813-0280, mailto: c.langenberg@ucl.ac.uk
} 
prompted us to study social mobility in relation to body dissatisfaction.

We are limited in specifying particular hypotheses regarding an association between body dissatisfaction and social mobility, since evidence on this issue is absent. However, we might draw from ecological data showing that the prevalence of body dissatisfaction and cultural pressures for women's thinness coincide in a graded manner with westernisation (and wealth) on a global scale, with women living in more westernised countries having greater body dissatisfaction than those living in non-westernised countries, with countries in transition intermediate between the two (Jaeger et al., 2002). Although ecological patterns of development over time must not be equated with associations during an individual's life history, we might suspect that intergenerational shifts in personal socio-economic position will show some association with body image at midlife. This can be accommodated within Bourdieu's discussion of lifestyles, in which he suggests that behaviours are guided by tastes which develop over time as a function of income and occupation, and social conditions (Bourdieu, 1984). Appearance investment (e.g., time and money spent on grooming), and other behaviours such as food selection, are shaped over time by one's social circumstances which are related to degree of wealth. Thus changes in social circumstances, or intergenerational movement between social classes, might entail a transition in terms of priorities related to weight and appearance, or a shift in experience of social norms regarding the appeal of particular body types. The importance of a transition from one socioeconomic position to another with respect to body image is not known. Perhaps the socio-economic circumstances of one's family of origin are so pertinent to later body image that intergenerational stability or mobility doesn't matter. Alternatively, perhaps current or adulthood socio-economic advantage or disadvantage is the primary influence, in which case the direction of transition in social class from childhood to adulthood would appear important to investigate. Furthermore, it is possible that these patterns differ for different dimensions of body dissatisfaction (i.e., weight versus general appearance), or by different indicators of socioeconomic position (i.e., occupation versus education).

Unlike in men, where a large degree of intergenerational continuity in social class (income or occupation) has been demonstrated, research is more limited in women and is complicated by shifts in mobility by marriage (Bartley, Sacker, \& Schoon, 2002). Studies suggest that downward mobility in women may be more likely due to a more limited range of jobs available to women in the recent past (Bartley et al., 2002). Therefore, social mobility (in addition to stability) would appear particularly important to study in relation to women's health. Furthermore, the generation of women currently in middle age (who comprise the sample for the present study) have lived through a sizeable increase in the extent of paid workforce participation by women (Krieger, Chen, \& Selby, 1999). Thus, intergenerational social mobility may be particularly pertinent to this cohort of women, and further clarification is needed regarding its association with health outcomes.

A finding of more body dissatisfaction among socially advantaged women could help to explain the social class gradient in obesity. This knowledge could help in the design of interventions to reduce the level of obesity among lower socio-economic position groups. It is possible that socio-economic position influences body size and body image through behaviours including healthy diet and regular physical activity, which are related to body size and are shown to be more common among socio-economically advantaged individuals (Colhoun \& Prescott-Clarke, 1996). Second, on a more theoretical level, the interplay between body size, body dissatisfaction, and social class is interesting from a social epidemiological perspective because it provides insight into class culture. While health behaviours and health status outcomes are reasonably straightforward to investigate, the present topic may help to get at more elusive lifestyle concepts as aesthetic preferences, ideals, and aspirations of distinction. It is unlikely that social class differences in health can entirely be explained in terms of easily measurable behaviours and outcomes; a more complete understanding of the social determinants of health demands insight into the more nebulous elements of one's socio-economic position.

Body dissatisfaction has previously been shown to be common among women in middle age (Allaz et al., 1998; McLaren \& Kuh, 2004), but studies are few. Dissatisfaction carries negative consequences for health and wellbeing among women of this age group, including elevated feelings of depression, lower quality of life, low energy levels (Reboussin et al., 2000), and avoidance of social situations, physical intimacy, and exercise (McLaren \& Kuh, 2004). Thus, additional research into its origins is desirable. We (McLaren \& Kuh) recently found that for any given weight, women from the nonmanual social classes in this age group were more dissatisfied about their body weight but not about their general appearance, than women from the manual classes. Inconsistencies in research on the social classdissatisfaction relationship might therefore reflect inconsistencies on the aspect of body dissatisfaction (weight or general appearance) assessed. The specific aims of this study are to examine current body esteem (weight and general appearance dimensions) as a function of (a) adult social class, (b) childhood social class, (c) educational qualifications, and (d) occupationally defined intergenerational social mobility among a large cohort of middle-aged British women. 


\section{Method}

\section{Participants}

The data source is the Medical Research Council National Survey of Health and Development, a followup study of 2547 women and 2815 men since their birth in March 1946 in England, Scotland, and Wales (Wadsworth, 1991; Wadsworth \& Kuh, 1997). This was originally a class-stratified sample which included all births to non-manual households, all births to agricultural workers, and a randomly selected 1 in 4 sample of the remaining families (Atkins, Cherry, Douglas, Kiernan, \& Wadsworth, 1981). When the participants were 47 years old an annual women's health postal survey was begun (Kuh, Wadsworth, \& Hardy, 1997) in order to study health in relation to the menopause transition. Of the original cohort, $6 \%$ had died, $9 \%$ were living abroad and not in contact with the study, $12 \%$ had refused to take part at earlier followups, 3\% could not be traced, and 19\% became nonresponders over the course of the eight women's health surveys. Of 1477 women who were sent a survey in 2000 (at age 54), 1308 responded indicating a response rate of $89 \%$ for 2000 , and representing $60 \%$ of the original 1946 cohort who had not previously died or emigrated.

\section{Variables}

Body dissatisfaction. When women were aged 54 years they completed the Body Esteem Scale (Mendelson, Mendelson, \& White, 2001) appearance (e.g., 'There are lots of things I'd change about my looks if I could', 10 items) and weight (e.g., 'Weighing myself depresses me', 8 items) subscales, which have shown good psychometric properties (Mendelson et al., 2001). Responses were made on a 5-point scale anchored by 'never' and 'always' and a mean score was taken across items (range 1-5). A higher mean score indicates more positive body esteem.

Social class. Data on father's occupation were collected at home visits when the women were 4,11 , and 15 years old. When the women were aged 26, 36, 43, and 53 years, data were gathered on each woman's occupation and her partner's, if applicable. These occupations were assigned to one of six classes according to the British Registrar General's social class classification; however in this study we treated social class as a dichotomous variable (manual, non-manual) because there was no evidence for a dose-response relationship between body esteem and social class across all six classes.

We defined adult social class in a gender-neutral manner, using either the woman's own or her partner's social class, whichever was highest (Krieger et al., 1999). If a woman did not have an occupation, her partner's class was used; if her partner did not have one, the woman's own class was used. This method of classifying socio-economic position is considered appropriate in light of women's increasing participation in the paid labour force (Krieger et al., 1999), a trend which calls into the question the traditional reliance on husband social class to classify women.

We assigned adult social class based on the predominant social class grouping across the four measurement occasions in adulthood, and in a similar way we assigned a childhood social class from the three measures of father's occupation. Women for whom there was no predominant grouping across childhood or adulthood (e.g., manual at age 4, non-manual at age 11, and missing data at age 15) were eliminated from the analyses ( $n=26$ for childhood social class, $n=193$ for adult social class). We then assigned social mobility category as stable non-manual (non-manual in both childhood and adulthood), upwardly mobile (manual in childhood and non-manual in adulthood), downwardly mobile (non-manual in childhood and manual in adulthood), or stable manual (manual in both childhood and adulthood).

On the basis of the highest educational qualifications achieved by age 26 years (Department of Education and Science, 1972) women were divided into those with no qualifications $(n=272,30.7 \%)$, ordinary secondary qualifications (O-level or equivalent) $(n=315 ; 35.6 \%)$, advanced secondary qualifications (A-level or equivalent) $(n=244,27.5 \%)$ and higher education (degree or equivalent) ( $n=55,6.2 \%)$.

Body mass index (BMI). Current BMI $\left(\mathrm{kg} / \mathrm{m}^{2}\right)$ was computed from height which was measured to the nearest $0.5 \mathrm{~cm}$ during a home interview when the women were aged 53 years, and weight which was self-reported by women on the postal survey when they were aged 54 years. An index of adolescent BMI was computed from measured heights and weights at age 15 years $(n=790)$, or age 11 years for those who were not measured at age $15(n=122)$.

\section{Analyses}

We conducted multiple regression analyses with body esteem as the outcome variable and childhood social class and BMI, and adult social class and BMI as independent variables. These analyses were repeated with educational qualifications as the independent variable among the slightly smaller sample of women with complete data on this variable $(n=886)$, unadjusted and adjusted for BMI. An overall test for an effect of educational qualifications was run, and this was followed by an analysis with dummy variables to contrast the different categories of education (no qualifications, ordinary secondary qualifications, advanced secondary qualifications, and degree level, with 
no qualifications as baseline). We also ran a regression analysis that included both adult social class and educational qualifications, to examine the relationship of these two variables to body esteem adjusted for one another. The relationship between social mobility and body esteem was investigated using a model including both childhood and adult social class and by testing for an interaction between the two. This was followed by an analysis with dummy variables to contrast the different categories of social mobility (stable non-manual, upward mobility, downward mobility, stable manual, with stable non-manual as baseline). These social mobility analyses were repeated defining adult social class (and therefore social mobility) based on women's own social class, or their partner's if they did not have one, to determine whether results differed from those obtained using the gender neutral definition.

All the analyses were repeated using a weighting procedure to adjust for the original sampling frame. As there was little or no change in the effect sizes the unweighted results are presented.

\section{Results}

Descriptive statistics are presented in Table 1. At midlife these women were slightly overweight on average $\left(\right.$ mean $\mathrm{BMI}=26.7 \mathrm{~kg} / \mathrm{m}^{2}$ ). In childhood, over half the sample was classified as from the manual social classes in accordance with the original sampling procedure. In adulthood over $80 \%$ of the women were classified as in the non-manual classes. Consequently, the two biggest groups were those who were 'always non-manual' and 'upwardly mobile' (those in the manual classes as a child and in the non-manual classes as an adult). In terms of educational qualifications women were split reasonably equally among no qualifications, ordinary secondary, and advanced secondary qualifications, with only a small minority of women $(6.2 \%)$ reaching degree level.

With appearance esteem as the outcome variable (Table 2, model 1), neither childhood nor adult social class showed a significant effect, whether unadjusted or adjusted for one another and/or BMI (adjusted: see footnotes $b-f$ in Table 2). With weight esteem as the dependent variable (Table 2, model 2), childhood social class showed a marginal positive effect when unadjusted and adjusted for adult social class (adjusted: see footnote $\mathrm{c}$ in Table 2), with women from non-manual backgrounds feeling more positively about their weight at midlife. However, this effect disappeared once BMI was adjusted for (adjusted: see footnotes $\mathrm{d}$ and $\mathrm{f}$ in Table 2), as childhood social class affected midlife weight esteem partly through adolescent BMI and particularly through adult BMI. This suggests that women from non-manual backgrounds were more satisfied with their weight at midlife because they were thinner throughout life (mean adolescent manual $\mathrm{BMI}=20.3 \mathrm{~kg} / \mathrm{m}^{2}$ vs. mean adolescent non-manual $\mathrm{BMI}=20.0 \mathrm{~kg} / \mathrm{m}^{2}, \quad p=0.1$, and mean adult manual $\mathrm{BMI}=28.2 \mathrm{~kg} / \mathrm{m}^{2}$ vs. mean adult non-manual $\left.\mathrm{BMI}=26.4 \mathrm{~kg} / \mathrm{m}^{2}, p<0.001\right)$. On the other hand, adult social class showed no relationship with weight esteem until BMI was controlled for (adjusted: see footnotes e and $\mathrm{f}$ in Table 2) when a strong negative relationship was revealed. This indicates that for any given weight, women in the non-manual classes in adult life felt more

Table 1

Descriptive statistics (mean and standard deviation or \%) on study variables among women from MRC NSHD ${ }^{\mathrm{a}} 1946$ birth cohort

\begin{tabular}{|c|c|c|c|c|}
\hline \multirow[t]{2}{*}{ Variable } & \multicolumn{2}{|c|}{ Unique $N$} & \multicolumn{2}{|c|}{ Complete data $(n=912)$} \\
\hline & $N$ & Mean (SD) or $\%$ & $N$ & Mean (SD) or $\%$ \\
\hline Body esteem appearance $(1-5)$ & 1288 & $3.3(0.72)$ & & $3.3(0.71)$ \\
\hline Body esteem weight $(1-5)$ & 1286 & $2.9(0.91)$ & & $2.9(0.90)$ \\
\hline Current BMI $\left(\mathrm{kg} / \mathrm{m}^{2}\right)$ & 1172 & $26.7(5.0)$ & & $26.7(5.0)$ \\
\hline Adolescent BMI $\left(\mathrm{kg} / \mathrm{m}^{2}\right)$ & 1135 & $20.2(3.1)$ & & $20.2(3.1)$ \\
\hline \multicolumn{5}{|l|}{ Childhood social class } \\
\hline Manual & 650 & $54.1 \%$ & 490 & $53.7 \%$ \\
\hline Non-manual & 552 & $45.9 \%$ & 422 & $46.3 \%$ \\
\hline \multicolumn{5}{|l|}{ Adulthood social class } \\
\hline Manual & 213 & 18.3 & 169 & $18.5 \%$ \\
\hline Non-manual & 949 & 81.7 & 743 & $81.5 \%$ \\
\hline \multicolumn{5}{|l|}{ Social mobility } \\
\hline Always manual & 159 & $14.7 \%$ & 138 & $15.1 \%$ \\
\hline Downward mobility & 40 & $3.7 \%$ & 31 & $3.4 \%$ \\
\hline Upward mobility & 403 & $37.3 \%$ & 352 & $38.6 \%$ \\
\hline Always non-manual & 478 & $44.3 \%$ & 391 & $42.9 \%$ \\
\hline
\end{tabular}

\footnotetext{
${ }^{\text {a }}$ Medical Research Council National Survey of Health and Development.
} 
Table 2

Results of multiple regression analyses predicting body esteem with social class and BMI ( $n=912$ women from MRC NSHD 1946 birth cohort)

\begin{tabular}{|c|c|c|c|c|c|c|}
\hline Variable & $\begin{array}{l}\text { Unadjusted regression } \\
\text { coefficient }(95 \% \mathrm{CI}) \\
p \text {-value }\end{array}$ & $\begin{array}{l}\text { Adjusted }^{\mathrm{b}} \text { regression } \\
\text { coefficient }(95 \% \mathrm{CI}) \\
p \text {-value }\end{array}$ & $\begin{array}{l}\text { Adjusted }^{\mathrm{c}} \text { regression } \\
\text { coefficient }(95 \% \mathrm{CI}) \\
p \text {-value }\end{array}$ & $\begin{array}{l}\text { Adjusted }{ }^{\mathrm{d}} \text { regression } \\
\text { coefficient }(95 \% \mathrm{CI}) \\
p \text {-value }\end{array}$ & $\begin{array}{l}\text { Adjusted }^{\mathrm{e}} \text { regression } \\
\text { coefficient }(95 \% \mathrm{CI}) \\
p \text {-value }\end{array}$ & $\begin{array}{l}\text { Adjusted }^{\mathrm{f}} \text { regression } \\
\text { coefficient }(95 \% \mathrm{CI}) \\
p \text {-value }\end{array}$ \\
\hline \multicolumn{7}{|c|}{ Model 1: Dependent variable: body esteem appearance } \\
\hline Adoles BMI $\left(\mathrm{kg} / \mathrm{m}^{2}\right)$ & $\begin{array}{l}-0.041(-0.06 \text { to } \\
-0.03) p<0.001\end{array}$ & $\begin{array}{l}-0.008(-0.02 \text { to } 0.01) \\
p=0.3\end{array}$ & - & $\begin{array}{l}-0.041 \quad(-0.06 \text { to } \\
-0.03) p<0.001\end{array}$ & - & $\begin{array}{l}-0.01(-0.03 \text { to } 0.01) \\
p=0.3\end{array}$ \\
\hline Adult BMI $\left(\mathrm{kg} / \mathrm{m}^{2}\right)$ & $\begin{array}{l}-0.05(-0.06 \text { to }-0.04) \\
p<0.001\end{array}$ & $\begin{array}{l}-0.047(-0.06 \text { to } \\
-0.04)\end{array}$ & - & - & $\begin{array}{l}-0.05(-0.06 \text { to }-0.04) \\
p<0.001\end{array}$ & $\begin{array}{l}-0.05(-0.06 \text { to }-0.04) \\
p<0.001\end{array}$ \\
\hline Child $\mathrm{SC}^{\mathrm{g}}$ & $\begin{array}{l}0.052(-0.05 \text { to } 0.2) \\
p=0.3\end{array}$ & - & $\begin{array}{l}0.04(-0.06 \text { to } 0.1) \\
p=0.4\end{array}$ & $\begin{array}{l}0.039(-0.06 \text { to } 0.1) \\
p=0.4\end{array}$ & - & $\begin{array}{l}-0.014(-0.11 \text { to } 0.08) \\
p=0.8\end{array}$ \\
\hline Adult $\mathrm{SC}^{\mathrm{g}}$ & $\begin{array}{l}0.07(-0.05 \text { to } 0.2) \\
p=0.2\end{array}$ & - & $\begin{array}{l}0.06(-0.06 \text { to } 0.2) \\
p=0.4\end{array}$ & 一 & $\begin{array}{l}-0.024(-0.14 \text { to } 0.09) \\
p=0.7\end{array}$ & $\begin{array}{l}-0.02(-0.1 \text { to } 0.1) \\
p=0.7\end{array}$ \\
\hline \multicolumn{7}{|c|}{ Model 2: Dependent variable: body esteem weight } \\
\hline Adoles BMI $\left(\mathrm{kg} / \mathrm{m}^{2}\right)$ & $\begin{array}{l}-0.10(-0.12 \text { to }-0.08) \\
p<0.001\end{array}$ & $\begin{array}{l}-0.03(-0.05 \text { to }-0.01) \\
p<0.001\end{array}$ & - & $\begin{array}{l}-0.09(-0.11 \text { to }-0.07) \\
p=0.001\end{array}$ & - & $\begin{array}{l}-0.03(-0.05 \text { to }-0.01) \\
p=0.001\end{array}$ \\
\hline Adult BMI & $\begin{array}{l}-0.11(-0.12 \text { to }-0.10) \\
p<0.001\end{array}$ & $\begin{array}{l}-0.10(-0.11 \text { to }-0.09) \\
p<0.001\end{array}$ & - & 一 & $\begin{array}{l}-0.11(-0.12 \text { to }-0.10) \\
p<0.001\end{array}$ & $\begin{array}{l}-0.10(-0.11 \text { to }-0.09) \\
p<0.001\end{array}$ \\
\hline Child SC ${ }^{\mathrm{g}}$ & $\begin{array}{l}0.10(-0.02 \text { to } 0.2) \\
p=0.08\end{array}$ & - & $\begin{array}{l}0.11(-0.01 \text { to } 0.2) \\
p=0.6\end{array}$ & $\begin{array}{l}0.07(-0.05 \text { to } 0.2) \\
p=0.2\end{array}$ & - & $\begin{array}{l}-0.004(-0.10 \text { to } 0.09) \\
p=0.9\end{array}$ \\
\hline Adult $\mathrm{SC}^{\mathrm{g}}$ & $\begin{array}{l}0.001(-0.2 \text { to } 0.2) \\
p=0.9\end{array}$ & - & $\begin{array}{l}-0.04(-0.2 \text { to } 0.1) \\
p=0.6\end{array}$ & 一 & $\begin{array}{l}-0.20(-0.32 \text { to }-0.08) \\
p=0.01\end{array}$ & $\begin{array}{l}-0.21(-0.3 \text { to }-0.09) \\
p=0.01\end{array}$ \\
\hline
\end{tabular}

${ }^{a}$ Medical Research Council National Survey of Health and Development.

${ }^{\mathrm{b}}$ Adjusted within BMI variables.

${ }^{\mathrm{c}}$ Adjusted within social class variables.

${ }^{\mathrm{d}}$ Adjusted within childhood variables (adolescent BMI, childhood SC)

${ }^{\mathrm{e}}$ Adjusted within adult variables (adult BMI, adult SC).

${ }^{\mathrm{f}}$ All variables mutually adjusted.

$\mathrm{g}_{0}=$ manual, $1=$ non-manual. 
Table 3

Results of multiple regression analyses predicting body esteem with highest educational qualifications and BMI $(n=886$ women from MRC NSHD 1946 birth cohort)

\begin{tabular}{lcc}
\hline & $\begin{array}{l}\text { Unadjusted regression } \\
\text { coefficient }(95 \% \mathrm{CI})\end{array}$ & $\begin{array}{c}\text { Adjusted for current BMI } \\
\text { regression coefficient (95\% CI) }\end{array}$ \\
\hline $\begin{array}{l}\text { Model 1. Dependent variable: body esteem appearance } \\
\text { Degree-level }\end{array}$ & $-0.13(-0.3$ to 0.07$)$ & $-0.21(-0.4$ to -0.01$)$ \\
A-level & $-0.12(-0.2$ to 0.00$)$ & $-0.20(-0.3$ to -0.08$)$ \\
O-level & $-0.07(-0.2$ to 0.05$)$ & $-0.11(-0.2$ to -0.01$)$ \\
No qualifications (reference group) & 0 & 0 \\
$p$-value & 0.27 & 0.006 \\
Model 2. Dependent variable: body esteem weight & & $-0.24(-0.5$ to -0.02$)$ \\
Degree-level & $-0.06(-0.3$ to 0.2$)$ & $-0.27(-0.4$ to -0.2$)$ \\
A-level & $-0.09(-0.3$ to 0.07$)$ & $-0.19(-0.3$ to -0.07$)$ \\
O-level & $-0.10(-0.2$ to 0.04$)$ & 0 \\
No qualifications (reference group) & 0 & $<0.001$ \\
$p$-value & 0.56 & \\
\hline
\end{tabular}

${ }^{a}$ Medical Research Council National Survey of Health and Development.

dissatisfied about their weight than women in the manual classes.

Educational qualifications were associated with poorer appearance esteem once we adjusted for BMI (unadjusted, $p=0.3$; adjusted for BMI, $p=0.006$ ). Table 3 model 1 (adjusted column) shows that women with any educational qualifications showed more appearance dissatisfaction relative to women with no qualifications. Thus, appearance esteem seems to be more sensitive to educational qualifications than to adult occupationally defined social class. In predicting weight esteem with educational qualifications (Table 3 model 2) we see a similar but stronger pattern (unadjusted $p=0.6$; adjusted for BMI $p<0.001$ ). Rerunning the adjusted education models including adult social class (not shown) we found that education is the component of adult socio-economic position that contributes most to body dissatisfaction: for appearance esteem, the effect of educational qualifications remained significant and the effect of adult social class remained non-significant; for weight esteem, the effect of educational qualifications remained significant $(p=0.002)$ and the effect of adult social class was reduced to nonsignificance $(p=0.3)$.

A significant interaction $(p=0.01)$ between childhood and adult social class emerged with appearance esteem as the outcome variable, such that an effect of childhood social class was seen in those in the manual social classes in adulthood. The size and direction of this interaction effect remained constant whether unadjusted or adjusted for BMI (not shown). Using dummy variables to represent contrasts between social mobility groups we found that the downwardly mobile group of women (non-manual in childhood, manual as adults) had significantly higher (better) appearance esteem than the stable non-manual women. Using regression coefficients from the interaction model adjusted for BMI we plotted the predicted appearance esteem scores for the four social mobility categories (Fig. 1a). This contrasts with the findings using weight esteem as the outcome variable where we did not detect a significant social class interaction effect. The greater effect of social classes of destination than of origin on weight esteem is clear in Fig. 1b: the predicted weight esteem values for the stable non-manual women and the upwardly mobile women were identical, as were the predicted weight esteem values for the downwardly mobile and the stable manual women. The same pattern of results was obtained when we repeated these social mobility analyses using the women's own social class (substituting her partner's only in the case that she did not have one) as the indicator of adult social class.

\section{Discussion}

To our knowledge this study is the first to examine the relationship between social class and body dissatisfaction from a longitudinal perspective, which enabled investigation of the effects of childhood social class and social mobility. Strengths of our study include prospectively collected data on occupation, education, and body weight and height from a large national sample. We also had social class data from both the woman and her partner, which made it possible to define social class as a gender-neutral household index. This is considered most appropriate for the study of women's health (Krieger et al., 1999).

Social mobility in the present study was defined based on several assessments of occupation taken across the 


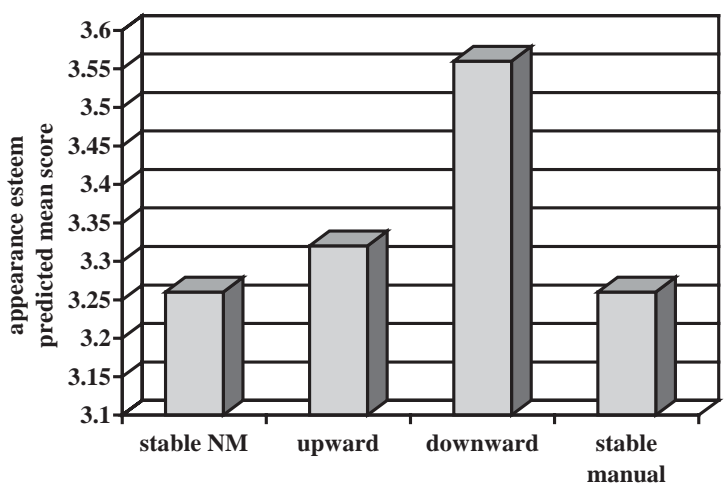

(a)

social mobility category

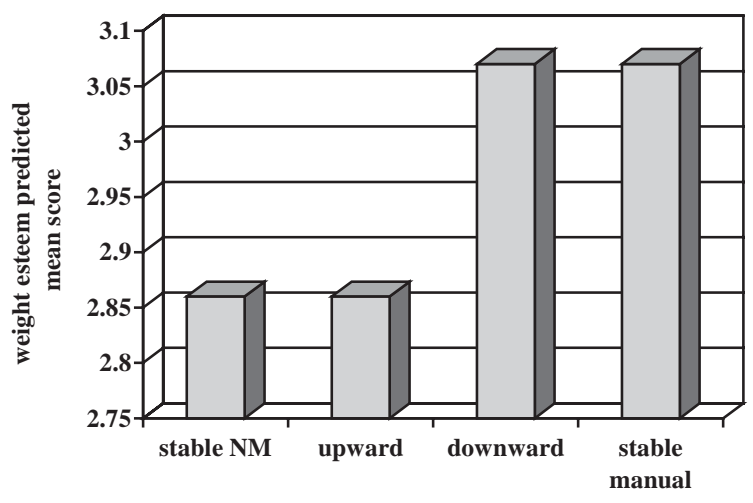

(b)

social mozility category

Fig. 1. (a) Midlife appearance esteem by category of social mobility. Notes: (1) appearance esteem: range 1-5, higher = better, (2) values computed from regression coefficients from interaction model, adjusted for adolescent and adult BMI, (3) reported for average adolescent and adult BMI. (b) Midlife weight esteem by category of social mobility, Notes: (1) weight esteem: range $1-5$, higher $=$ better, (2) values computed from regression coefficients from additive model, adjusted for adolescent and adult BMI, (3) reported for average adolescent and adult BMI.

life span, which we believe adequately classifies women on this dimension. We acknowledge that the downwardly mobile women as defined in this study comprised only a very small percentage $(3 \%)$ of our sample, and thus caution should be exercised in interpreting our results. A larger sample of women with this social mobility profile would be useful for confirming our results. We note that other studies have also shown a small percentage of women with downward intergenerational mobility, relative to other social mobility categories (e.g., 10\% downwardly mobile among women with a mean age of 51 years in 1989-1990; Krieger, Chen, \& Selby, 2001).

We found no evidence for a relationship between appearance esteem and either childhood or adult social class. At first sight this would appear to contradict Bourdieu's (1984) discussion of social class differences in time and effort invested in the body. However, the effect of social mobility, with the small group of downwardly mobile women reporting more satisfaction with their appearance relative to the stable non-manual group, may reconcile the two. It suggests that intergenerational transition between classes is necessary to detect such an effect of 'class social climate' on body esteem. Downwardly mobile women may be particularly influenced by the lower appearance investment that Bourdieu suggests characterises the manual classes (keeping in mind that 'appearance investment' can be a social or group-level attribute and not just an individual-level characteristic). Having come from a non-manual background, such manual class attitudes and values may be especially salient or influential to these women, and thereby exert a demonstrable (protective) effect on appearance esteem.

Findings with weight esteem require a different explanation. For this outcome, the marginal positive effect of childhood social class that disappeared once we adjusted for adolescent and particularly adult BMI, and the negative effect of adult social class that emerged only when we adjusted for BMI, suggests that the effects of childhood and adult social class on weight esteem operate through different pathways. Women from a non-manual background are thinner in adolescence and particularly in adult life and this explains why they are more satisfied with their weight at middle age. Other studies have also shown a similar relationship between childhood social class and adult BMI (Power \& Parsons, 2002). The reasons are not entirely known but may involve healthier diets and more physical activity. The relative thinness in adulthood and to a lesser extent in adolescence of those from non-manual backgrounds then facilitates weight satisfaction. Women in the non-manual classes in adult life were thinner and they were more dissatisfied with their weight, for a given BMI. This pattern probably implicates sociocultural factors such as the cultural message that thinness is a prerequisite for beauty and "thin is never thin enough'.

At each level of BMI, women with no educational qualifications at age 26 years felt more positively about their weight and appearance at age 54 than those with qualifications. The effect was stronger for weight esteem than for appearance esteem, but the pattern was similar: women with degrees and/or advanced secondary qualifications had the lowest body esteem, women with no qualifications had the highest esteem, and women with ordinary secondary qualification were intermediate between the two. Barber (1998) has shown that over time, as women's levels of education have increased, ideal standards for women's bodily attractiveness have become more slender. Although we should not confuse 
such ecological data with individual-level associations, we might still suggest that better-educated women are increasingly attuned to or influenced by these standards and are therefore more likely to evaluate themselves (negatively) against them.

Comparing the findings based on education and adult social class (both indicators of adult socio-economic position) we see that for weight esteem the findings were similar for both indicators (higher position $=$ more dissatisfaction for a given BMI). However for appearance esteem this relationship was only borne out for education. Further, the relationship between weight esteem and adult social class was eliminated when education was included in the model. For this cohort of women, education appears to be the key status variable contributing to body dissatisfaction. Education may have the effect of increasing women's awareness of news and media, in which women are often portrayed in a way that emphasises their appearance. Women's fashion magazines for example are considered to contribute to body dissatisfaction among girls (Field et al., 1999), and if better-educated women are the ones reading these magazines then they may be at greater risk. If this is the case then it is unfortunate that education does not promote a more critical evaluation by these women of the way females are portrayed in the mass media. Another possibility is that better-educated women are more familiar with health education messages, which have extolled the virtues of a healthy diet and body, and such messages may inadvertently foster body dissatisfaction through a focus on ideal diet and body weight. A final explanation concerns the relationship between women's education levels and expectations for personal achievement. Perhaps more highly educated women show higher achievement expectations, which generalise to include expectations about physical appearance. Since contemporary standards for women's physical attractiveness are nearly impossible to meet, 'achievement' in this arena will rarely be met and body dissatisfaction will be more likely. This explanation is related to a feminist view on eating disorders, which holds that within a patriarchal society women are limited in the amount of 'space' they can occupy. As women gain in education and economic power, they must compensate by taking up a smaller amount of physical space-evidenced by the smaller body size sought by many women and achieved by the few with anorexia nervosa (Bordo, 1993). As an extension, women who achieve or excel academically or economically may compensate with insecurity or dislike for their physical self.

To conclude we assert that an understanding of the relationship between social status and body image requires that several distinctions be made: weight versus appearance satisfaction, occupation versus education, and current socio-economic position versus intergenerational stability or mobility.

\section{Acknowledgements}

This study of women's health is funded by the UK Medical Research Council.

At the time of writing, L. McLaren was supported by a Doctoral Fellowship from the Social Sciences and Humanities Research Council of Canada.

\section{References}

Allaz, A.-F., Bernstein, M., Rouget, P., Archinard, M., \& Morabia, A. (1998). Body weight preoccupation in middle-age and ageing women: A general population survey. International Journal of Eating Disorders, 23, 287-294.

Atkins, E., Cherry, N., Douglas, J. W. B., Kiernan, K. E., \& Wadsworth, M. E. J. (1981). The 1946 British birth cohort: An account of the origins, progress, and results of the national survey of health and development. In S. A. Mednick, A. E. Baert, \& B. Phillips Bachmann (Eds.), Prospective longitudinal research: An empirical basis for the primary prevention of psychosocial disorders (pp. 25-30). Oxford: Oxford University Press.

Barber, N. (1998). Secular changes in standards of bodily attractiveness in women: Tests of a reproductive model. International Journal of Eating Disorders, 23, 449-454.

Bartley, M., Sacker, A., \& Schoon, I. (2002). Social and economic trajectories and women's health. In D. Kuh, \& R. Hardy (Eds.), A life course approach to women's health (pp. 233-254). Oxford: Oxford University Press.

Bourdieu, P. (1984). Distinction: A social critique of the judgement of taste. London: Routledge.

Bordo, S. (1993). Unbearable weight. Los Angeles: University of California Press.

Brumberg, J. J. (1988). Fasting girls: The history of anorexia nervosa. New York: Vintage Books.

Colhoun, H., \& Prescott-Clarke, P. (1996). Health survey for England 1994. London: HMSO.

Department of Education and Science (1972). Burnham further education committee grading courses. London: HMSO.

Feingold, A., \& Mazzella, R. (1998). Gender differences in body image are increasing. Psychological Science, 9, 190-195.

Field, A. E., Cheung, L., Wolf, A. M., Herzog, D. B., Gortmaker, S. L., \& Colditz, G. A. (1999). Exposure to the mass media and weight concerns among girls. Pediatrics, 103, E36-E40.

Gortmaker, S. L., Must, A., Perrin, J. M., Sobol, A. M., \& Dietz, W. H. (1993). Social and economic consequences of overweight in adolescence and young adulthood. The New England Journal of Medicine, 329, 1008-1012.

Groesz, L. M., Levine, M. P., \& Murnen, S. K. (2002). The effects of experimental presentation of thin media images on body satisfaction: A meta-analytic review. International Journal of Eating Disorders, 31, 1-16.

Hardy, R., Wadsworth, M., \& Kuh, D. (2000). The influence of childhood weight and socioeconomic status on change in adult body mass index in a British national birth cohort. International Journal of Obesity, 24, 725-734. 
Jaeger, B., Ruggiero, G. M., Edlund, B., Gomez-Perretta, C., Lang, F., Mohammadkhani, P., Sahleen-Veasey, C., Schomer, H., \& Lamprecht, F. (2002). Body dissatisfaction and its interrelations with other risk factors for bulimia nervosa in 12 countries. Psychotherapy and Psychosomatics, 71, 54-61.

Jeffery, R. W., Adlis, S. A., \& Forster, J. L. (1991). Prevalence of dieting among working men and women: The healthy worker project. Health Psychology, 10, 247-281.

Jeffery, R. W., \& French, S. A. (1996). Socioeconomic status and weight control practices among 20- to 45-year-old women. American Journal of Public Health, 86, 1005-1010.

Krieger, N., Chen, J. T., \& Selby, J. V. (1999). Comparing individual-based and household-based measures of social class to assess class inequalities in women's health: A methodological study of 684 US women. Journal of Epidemiology and Community Health, 53, 612-623.

Krieger, N., Chen, J. T., \& Selby, J. V. (2001). Class inequalities in women's health: Combined impact of childhood and adult social class - a study of 630 US women. Public Health, $115,175-185$.

Kuh, D. L., Wadsworth, M., \& Hardy, R. (1997). Women's health in midlife: The influence of the menopause, social factors and health in earlier life. British Journal of Obstetrics and Gynaecology, 104, 923-933.

Langenberg, C., Hardy, R., Kuh, D., Brunner, E., \& Wadsworth, M. (2003). Central and total obesity in middle aged men and women in relation to lifetime socioeconomic status: Evidence from a national birth cohort. Journal of Epidemiology and Community Health, 57, 816-822.

McLaren, L., \& Kuh, D. (2004). Body dissatisfaction in midlife women. Journal of Women and Aging. in press.

Mendelson, B. K., Mendelson, M. J., \& White, D. R. (2001). Body-esteem scale for adolescents and adults. Journal of Personality Assessment, 76, 90-106.

Orbach, S. (1978). Fat is a feminist issue: The anti-diet guide to permanent weight loss. New York: Paddington Press.

Ogden, J., \& Thomas, D. (1999). The role of familial values in understanding the impact of social class on weight concern. International Journal of Eating Disorders, 25, 273-279.
Power, C., \& Parsons, T. (2002). Overweight and obesity. In D. Kuh, \& R. Hardy (Eds.), A life course approach to women's health (pp. 304-328). Oxford: Oxford University Press.

Reboussin, B. A., Rejeski, W. J., Martin, K. A., Callahan, K., Dunn, A. L., King, A. C., \& Sallis, J. F. (2000). Correlates of satisfaction with body function and body appearance in middle- and older aged adults: The activity counseling trial (ACT). Psychology and Health, 15, 239-254.

Rodin, J., Silberstein, L., \& Striegel-Moore, R. (1985). Women and weight: A normative discontent. In T. B. Sonderegger (Ed.), Nebraska symposium on motivation: Vol. 32. Psychology and gender (pp. 267-307). Lincoln, NE: University of Nebraska Press.

Sargent, J. D., \& Blanchflower, D. G. (1994). Obesity and stature in adolescence and earnings in young adulthood. Archives of Paediatric and Adolescent Medicine, 148, 681-687.

Sobal, J. (1991). Obesity and socioeconomic status: A framework for examining relationships between physical and social variables. Medical Anthropology, 13, 231-247.

Sobal, J., \& Stunkard, A. J. (1989). Socioeconomic status and obesity: A review of the literature. Psychological Bulletin, 105, 260-275.

Spitzer, B. L., Henderson, K. A., \& Zivian, M. T. (1999). Gender differences in population versus media body sizes: A comparison over four decades. Sex Roles, 40, 545-565.

Wadsworth, M. E. J. (1991). The imprint of time: Childhood, history and adult life. Oxford: Oxford University Press.

Wadsworth, M. E. J., \& Kuh, D. J. L. (1997). Childhood influences on adult health: A review of recent work in the British 1946 National Birth Cohort Study, the MRC National Survey of Health and Development. Paediatric and Perinatal Epidemiology, 11, 2-20.

Wardle, J., \& Griffith, J. (2001). Socioeconomic status and weight control practices in British adults. Journal of Epidemiology and Community Health, 55, 185-190.

Wardle, J., Waller, J., \& Jarvis, M. J. (2002). Sex differences in the association of socioeconomic status with obesity. American Journal of Public Health, 92, 1299-1304. 